\title{
Antonovsky's point of view on determinants of immigrant integration
}

\section{Introduction}

The difficulties of integrating immigrants has existed for centuries. There are societies that in fact are a conglomeration of various immigrant groups (e.g. USA, Brazil). In the last hundred or so years, there has been a need to take in people from the former colonies and relocate them in several European countries, which contributed to gaining experience related to the possibilities integrating newcomers from foreign cultures (e.g. England, France). In the last few years, due to the wave of immigration caused by the wars in the Middle East, abilities to integrate newcomers have become extraordinary important.

It should be noted that the sociological, practical problem is twofold. It is necessary to consider the willingness and ability to integrate immigrants in the society to which they came. In addition, there are variable degrees of difficulty to assimilate immigrants by the host communities.

We think that Aaron Antonovsky expressed valuable remarks on these processes. ${ }^{1}$ They are useful even now, years after the time they were expressed because they were uttered by an extremely competent researcher in this field. Antonovsky is the author of a very momentous theory which tries to answer the question: "What are the (psychological and social) origins of health?" It is considered in the realm of his theory of 'salutogenesis'. At the same time he came from a family of immigrants and he was personally an immigrant, first in the United States, and then in Israel (a completely 'immigrant' country), where he also conducted extensive research on the relationship between well-being and health, depending on the degree of integration of newcomers.

\section{Antonovsky's insights in to cultural sources of stress}

Immigrants generally come from countries of a very distinct culture. The gap between their nature and customs, beliefs and values of the nation they would like to integrate or at least coexist with is of course very different. Antonovsky noted, however, that as a rule the aspirations of young immigrants are lower than their peers living from birth in a particular cultural environment. He termed this rule "ethnic handicap. These phenomena have various intensities, but usually disparity occurs between immigrants' aspirations and the possibilities of their realization.

The negative impact of the distinct culture is greater when the local culture is sophisticated, when it changes fast and when it is reluctant, discriminatory, or even hostile to newcomers. It is worth quoting the original statement summarizing the essence of this 'ethnic handicap'. The more the integration, the greater the ease in making sense of the messages. These are the core problems of minority groups, immigrant workers, lower class persons, illiterates $[\ldots]$ and of women.To the degree that they cannot escape into a viable subculture, they are bombarded by noise and by brutal information". 2
Volume I Issue 2 - 2017

\author{
Andrzej Brodziak,' Alicja Rozyk Myrta, ${ }^{2}$ \\ Agnieszka Wolinska² \\ 'Institute of Occupational Medicine and Environmental Health, \\ Medical University of Silesia in Katowice, Europe \\ ${ }^{2}$ Institute of Nursing, University of Applies Sciences, Nysa, \\ Europe
}

Correspondence: Andrzej Brodziak, Institute of Occupational Medicine and Environmental Health Koscielna St. 13, 4I - 200 Sosnowiec, Poland, Europe, Tel (48 32) 26608 85, Fax (48 32) 266 II 24, Email andrzejbrodziak@wp.pl

Received: October 27, 2016 | Published: March 31, 2017

\section{The importance of so-called 'cultural equip- ment'}

According to Antonovsky's point of view, the possibility of immigrants functioning effectively in a foreign culture depends on the possession of so-called 'Generalized Resistance Resources' (GRR), which is called in other words the possession of 'effective cultural equipment' (ECE). He argued that it is important that young people grew up in a culture that allows the release of their personal potential and points to patterns enabling the realization of their aspirations. The more stable the culture is, the easier the acquisition of GRR is. Again, it is worth quoting the original worded summary:

,... a culture provides its members, group and individual, with ready answers, clear, stable, integrated; with keening for a death, an explanation for pain, a ceremony for crop failure, and a form for disposition and accession of leaders. At the other extreme, which at times becomes a reality for individuals and groups, there is only utter chaos; there are no answers. Ready answers provided by one's culture and its social structure are probably the most powerful GRR of all. ${ }^{3}$

\section{Pro-health quality of receiving culture}

Antonovsky as the author of salutogenesis tries to convince his readers, stressing that the considered culture should promote a life course trajectory enabling citizens to experience life as comprehensible, manageable and meaningful (three components of Antonovsky's basic concepts of coherence). Comprehensibility arises from a stable culture that sends consistent messages to people, manageability is created by a culture that gives people the tools to live up to norms set by the culture, and meaningfulness is supported by a culture that values the role of people and gives them a place in the world . The original summary on this aspect of the discussion is as follows:

“.. Clearly, if one has a high intelligence, lots of money, or a clear ego identity or lives in a stable, integrated culture - to mention some 
GRRs - there will be consequences not only for the emergence of a strong SOC, and therefore health, but for other areas of well-being as well.",

\section{The practical manifestation of integration}

Carina Benz discussing Antonovsky's insights also indicates his remarks related to the manifestation of a positive outcome of the process of integration. ${ }^{1}$ Hence, integration occurs when newcomers participate in local cultural activities. This was confirmed by research by Forssén. ${ }^{5} \mathrm{He}$ showed that older women who participated in cultural activities such as theater and concerts experienced "increased strength, comfort and self-esteem, and reduced feelings of loneliness".

\section{Average and desirable features of host com- munity}

It is known that in most countries of the world, including most EU countries, the attitude of residents is now generally averse to immigrants. Many politicians seeking election to the highest state positions declare total opposition to accepting immigrants. At the same time, analysts of social and political phenomena predict that the problem of immigration into the EU cannot be stopped. Analyses of the causes of the negative attitude of the majority of EU societies have been performed. It has been shown that there is an inverse relationship between the ability to enter into friendship and acceptance of immigrants. ${ }^{6}$ It was also shown that the attitude of young men and girls towards immigrants depends on the beliefs and attitudes of their parents. ${ }^{7}$ Effective psychometric tools to measure the degree of xenophobia have been developed. ${ }^{8}$

At the same time, sociologists' analyses show that the low fertility rates and the resulting depopulation of most EU countries will inevitably force scientists, publicists and politicians to consider and discuss further the topic of attitudes towards immigrants. The inability to halt the processes of globalization in all kinds of human endeavors inclines to continuing attempts to develop effective ways to realize the integration of immigrants..$^{9,10}$

\section{The key to solve the problem}

It seems that if we recognize that the aversion to people of different skin color, different customs, religion, different understanding of social order are in fact very abstract obstacles whose significance is relative and usually has a character of 'prejudices', then a solution to the problem is at hand. The solution depends merely on effectiveness in terms of: (1) the formulation of theoretical, however clear, convincing 'explanations' of the occurring prejudices and (2) from abilities to organize the transfer of these theories to the consciousness of society.

\section{Acknowledgements}

I am grateful for Christine Frank - Szarecka for the linguistic corrections of the manuscript.

\section{Conflict of interests}

The authors declare that they have no competing interests.

\section{References}

1. Carina Benz, Torill Bull, Maurice Mittelmark, et al. Culture in salutogenesis: the scholarship of AaronAntonovsky. Glob Health Promot. 2014;21(4):16-23.

2. Antonovsky A. The structural sources of salutogenic strengths. Personality and Stress: Oxford: John Wiley, Son, editors. Individual Differences in the Stress Process. USA; 1991. p. 67-104.

3. Antonovsky A. Health, Stress, and Coping. Jossey-Bass Publishers, San Francisco, USA; 1979.

4. Antonovsky A. Unraveling the Mystery of Health. Jossey-Bass Publishers, San Francisco, USA; 1987.

5. Forssén ASK. Humour, beauty, and culture as personal health resources: Experiences of elderly Swedish women. Scand J Publ Health 2007;35(3):228-234.

6. van Zalk MH, Kerr M, van Zalk N, et al. Xenophobia and tolerance toward immigrants in adolescence: cross-influence processes within friendships. J Abnorm Child Psychol. 2013;41(4):627-639.

7. Gniewosz B, Noack P. Parental influences on adolescents' negative attitudes toward immigrants. $J$ Youth Adolesc. 2015;44(9):1787-802.

8. van der Veer K, Ommundsen R, Yakushko O, et al. Cross-national measure of fear-based xenophobia: development of a cumulative scale. Psychol Rep. 2011;109(1):27-42.

9. van Zalk MH, Kerr M. Developmental trajectories of prejudice and tolerance toward immigrants from early to late adolescence. $J$ Youth Adolesc. 2014;43(10):1658-1671.

10. Ommundsen R, Van der Veer K, Yakushko O, et al. Exploring the relationships between fear-related xenophobia, perceptions of out-group entitativity, and social contact in Norway. Psychol Rep. 2013;112(1):109-124. 